\title{
Metropolitan Vision Making - Using Backcasting as a Strategic Learning Process to Shape Metropolitan Futures
}

\author{
NEUVONEN, Aleksi ${ }^{1}$, ACHE, Peter $^{2}$ \\ 1 Demos Helsinki AND Nijmegen School of Management, Radboud University Nijmegen \\ 2 Nijmegen School of Management, Radboud University Nijmegen
}

\begin{abstract}
The need for new forward looking tools in urban planning is immense: The new functional relations and structures are stretching beyond our capacity to 'rationally' capture modern metropolitan spaces (Neuman \& Hull 2009). At the same time cities struggle to find tools to help manage a long-term transition towards a low-carbon, resource smart economy.
\end{abstract}

In 2006-2007 municipalities in the Helsinki metropolitan region organised an international ideas competition called Greater Helsinki Vision 2050. The competition aimed at being "a visionary adventure [...] [t]he chance to dream afresh, to accept current realities, not as negative restraints but as spurs to the imagination." The competition drew a good number of entries and triggered a subsequent analysis process to harvest the most fruitful ideas of the competition, which brought together awarded participants of the competitions, local planning professionals and citizens. (Ache 2011)

This paper explores the role of (normative) visions on the future of metropolitan spaces as a tool for facilitating transition.

This is done through a 'thick description' (Geertz 1973) of one example case, namely the Greater Helsinki Vision 2050 ideas competition and subsequent vision process. This thick description is based on a backdrop and an elaboration of a literature-based mapping of tools for managing long-term transformation in metropolitan spaces.

The focus of this paper is the question of strategic learning by the actors involved in an urban transition process. How can different tools of the imagination (long-term goal on GHG emissions reductions, backcasting scenarios, participatory visioning exercises) bring something un-manageable like metropolitan spaces and the wicked problems they face within the domain of managing? How can different actors experience strategic learning on renewed perspectives of different opportunities that alternative futures could provide? What would a new integrated 'incrementalism with perspective' (Ganser, Siebel \& Sieverts 1993) approach to managing metropolitan transitions look like? This paper extends the idea of 'emancipatory backcasting' as a generic tool for engaging stakeholders in transition processes to cover metropolitan futures (Neuvonen et al. 2014).

Keywords: Vision, transition Backcasting Scenarios, Metropolitan region, Incrementalism with Perspective, Learning

\section{Introduction: Metropolitan Development beyond the Reach of Planning}

Metropolitan regions are the urban phenomenon of our age. Concentration of population and economic activities in large urban settings with new forms of dynamism is a development taking place on every continent. While these new urban mega-structures attract increasing amounts of creative power, investments, and different forms of economic activity, they also present unforeseen challenges to urban governance: the capacity to 'configure' metropolitan development is missing, and this capacity will most likely not be found in the same direction as the previous forms of urban governance. (Ache 2011)

Hence the need for new forward-looking tools in urban planning is immense: the new functional relations and structures are stretching beyond our capacity to 'rationally' capture modern metropolitan spaces (Neuman \& Hull 2009). At the same time both cities and metropolitan regions struggle to find tools to help manage a long-term transition towards a low-carbon, resource smart economy.

At the same time one thing is evident: "we can only manage if we can imagine" (Ache 2011). More specifically: we will not find tools to manage and govern metropolitan regions, new form of urban development in quantity and quality, unless we hone our capacity to develop visions together with diverse groups of peers, experts and other stakeholders. Hence the metropolitan era is in search of new tools for visioning - creating long-term perspectives on futures that are at the same time desirable and accessible enough for a wider range of groups of people, so that they can provoke positive action. That means that there has to be different types of alternative futures created, depicting reality from 
different angles and on different levels, and reflecting different priorities of action based on differing normative intentions by different groups of people.

Metropolitan regions can be interpreted as a new spatial category with requirements for governance (Ache 2013). Metropolitan regions are 'islands floating in deserts' (Veltz 2004) or 'spiky structures in geography' (Florida 2005): metropolises epitomise the global economy in the sense that it is in these places where competition for the best talent, the greatest investment flows, and the most disruptive innovations is the fiercest. Because of this constant search for competitiveness, metropolitan governance defies the traditional structures of governance that originate from the era of nation states (Alanen et al 2010). And because of this imperative of competitiveness metropolitan regions are in constant conflict with the need for local anchoring in urban societies formed by various citizen groups (Massey 2005). Will it still be possible to design cohesive places or will the divides in metropolitan societies increase further (Taylor 2004)?

The metropolis is not a geographic unit with clear boundaries or legally defined administrative structures as much as it is a metaphor that links past experiences and perceptions in a comparative fashion to current times. It can also be understood as a model, a metaphor elaborated with further details, frequently using existing role models - in particular other rivalling metropolises - elsewhere (Ache 2011).

However, it is not only metropolitan development as a new level and form of urban change that poses an invincible challenge to prevailing methods and structures of urban governance. Wicked problems with no definitive formulation, no stopping rule, no true-or-false solutions, unique solutions or one-shot solutions (as defined by e.g. Rittel \& Webber 1973) create a new type of burden for any type of governance. Perhaps the best example of a wicked problem is global climate change. The EU countries have agreed to cut their GHG emission by $80 \%$ by 2050 (European Commission 2011) and the same target has been adopted in most European national policies. A substantial number of cities in Europe and elsewhere have also set similar, measurable, time-bound targets for slashing their emissions to a level considerably lower than that of today.

These radical emissions reduction levels (-80-95\%) have extended the usual time horizon of political debate and introduced future carbon intensity of technical and social systems as relevant planning principles for cities (Neuvonen et al. 2014). Hence the challenge goes far beyond an energy-carbon issue, covering such territories of everyday life as housing, mobility, and food, and basic categories of society such as work, enterprise and technology. Most of these practices are largely determined by large-scale, slow-changing economic, social and technical systems. The need for tools to manage these decades-long complex processes has initiated new approaches on how to coordinate engagement of and collaboration between different stakeholders required for achieving systemic transition. (Fuenfschilling \&Truffer 2014)

To sum up: a substantial amount of the population in both developed and developing countries will live in metropolitan regions and an even greater proportion of all economic activity takes place in these metropolises. At the same time we are confronted with an understanding that these urban mega-structures escape the power of prevailing methods and tools for managing urban development, meanwhile creating new types of tensions that even dilute the strength of existing structures of governance. We are also faced with the fact that the physical boundaries of our world (in the form of the climate system's capacity to absorb greenhouse gases) are (again) setting limits on how we plan our cities and on the lifestyle pattern people adopt in the urban context. Hence the need to alter large parts of our physical infrastructure energy production, traffic systems, buildings and urban structures - into a low-carbon mode within a timeframe of a couple of decades.

The question remains: how to build new methods of governance that take hope and desirable futures as a starting point? This paper presents a framework of ideas that provides theory and methods to address this cluster of challenges. This is done by focusing on the case of the Greater Helsinki Vision 2050 ideas competition and the subsequent vision process. Our intention is to analyse, by way of a 'thick description' (Geertz 1973) how new forms of open and vision-led processes could provide tools for a new era of managing urban change in metropolises. The case is analysed through the theoretical lens of incrementalism with perspective (Ganser, Siebel \& Sieverts 1993).

We further suggest backcasting scenarios as a method to implement vision-making processes. They were used in the GHV process, as a way to implement some of the main principles and traits of incrementalism with perspective. Backcasting can be seen as a tool to facilitate strategic learning (Giddens 1984) for a variety of stakeholders and actors on opportunities and constrains of the future thus creating 'perspective' for desirable development.

\section{Theory: Incrementalism with Perspective}

Most other metropolitan regions in industrialised western societies are in a situation where paths towards renewing the city and its structures are restricted: the replacement rate of the existing building stock is low and extensive mega- 
projects usually face challenges such as the lack of vacant spaces, narrow funding frames and fragmented political support. Traditionally forward-looking policies and progressive business initiatives have been characterised by topdown planning and visible lighthouse projects that have initiated change in different corners of society, often without paying enough attention to the conflicts between different stakeholders that the projects impose. (Campbell 1996). In the post-modern, networked, neo-liberal slow growth European early 21st century societies, these types of 'great leaps' turn out to be very difficult to undertake. Hence the focus is shifting more towards change that happens incrementally via retrofitting projects and stimulating the local economy to create new jobs in services.

In complex settings, such as the ones posed by metropolitan spaces, the interactions between land-use systems are of such a magnitude that full rational control will ultimately fail (Government Office for Science 2010). These types of rigid and multiplying factors quite often make the future perspective rather short and even evoke a sense of immobility and friction (good examples of this are the zoning practices and growth boundaries that cause building projects to appear further in the fringes, or large scale regional public transit projects that get blocked due to opposition in some of the municipalities). The quality of the metropolitan region as a transitional object (Ache 2011) and as a 'soft space' (Allmendinger \& Haughton 2010) can be seen as a way to shift focus away from the constraints of the existing reality and towards its potential, embedded mainly in human capital, i.e. the skills, motivations and ambitions of people and their capacity for collaboration. Hence we need to acknowledge some type of an incremental mode of planning in industrialised societies with an extensive built urban environment already in place.

One proposed approach is incrementalism with perspective, as practiced in relation to the International Building Exhibition Emscherpark in Germany in the 1990s (Braybrooke \& Lindblom, cited in Hutter 2006; Ganser, Siebel \& Sieverts 1993). In the approach of this paper the perspective is understood as provided by the vision, an imagination of the future. That imagination is then combined and complemented through incremental action by various institutions. There are various spatial constellations that can be interpreted as preferred solutions. Based on such arguments as well as on the previous interpretation, this text in fact proposes to reverse the argument made by Neuman and Hull (2009): "We can manage, if we can imagine!" (Ache 2013)

How could the different tools of imagination bring something un-manageable within the domain on managing? Planning is and should be the 'mobilisation of hope' (Hillier \& Healey 2008), and planners certainly have a 'bias for hope' (Friedmann 2002.) In a poly-centric (literal meaning) setting with distributed resources and responsibilities, a strong vision can give form to hope and nudge people and actors to take a responsible step forward and to re-interpret and re-adjust existing policies and practices (Ache 2011). In the core of this type of process is strategic learning: a process in which actors understand surrounding conditions and structures in a new way and subsequently start to perceive new opportunities for path-depedency breaking action (Allmendinger 2009).

The authors of this article see incrementalism with perspective as an approach that could serve as a generic model on which to develop governance for metropolitan regions. However, what is still needed are tools and methods through which imagination by individuals can be conjoined into a shared 'perspective' or 'vision'. Previously we have suggested such models as 'territorial response capacity' (Ache 2011), in which expertise, foresight, norms, and strategy have been chosen with a similar interest and 'emancipatory backcasting' (Neuvonen et al. 2014) that aims not to identify but to non-omit key actors and to empower key actors to understand their role in the formation of sustainable futures. In this article we interpret the Greater Helsinki Vision 2050 process as an exercise of 'territorial response capacity' and 'emancipatory backcasting'.

\section{Method: Backcasting Scenarios}

To facilitate understanding of the underlying logic of society-wide transformations such as emergence of low-carbon society, different types of future scenarios are often employed. Because the context is defined by a long-term target (e.g. emissions level in 2030 or 2050), the scenarios are usually constructed following the so-called backcasting approach: looking back from a future where a desired goal has been met and creating decisive steps and pathways back to the present day. The most suitable domains for this type of a normative approach have been large energy and transportation systems, where long-term investments in infrastructure and economic incentives are the determining factors, and thus quantified models depicting possible pathways can be based on these techno-economic drivers. (Neuvonen et al. 2014)

The most defining characteristic of backcasting is the normative approach to the future that it entails instead of a purely descriptive one. The typical first step in a backcasting scenario process is to assume defining criteria for a desirable future and to build a feasible and logical path between states of the future and the present based on it. (Neuvonen et al. 2014)

Many authors have justified the need for a normative scenario approach by referring to historical circumstances and emerging disruptions in that development (Quist \& Vergrat 2006; Dreborg 1996). Backcasting is a relevant option when forecasting studies indicate that long-term developments seem to lead to undesirable outcomes (Höjer \& Mattson 2000). 
Backcasting scenarios allow for new options to be considered reasonable, thus widening the perception of what could be feasible and realistic in the long-term (e.g. Dreborg 1996; Höjer \& Mattsson 2000). (Neuvonen et al. 2014).

To this day the majority of scenarios on urban futures focus on technical systems, and are by definition target-oriented, focusing on normative, quantitatively defined goals and answering the question "what can change." This approach can be contrasted with pathway-orientated backcasting and action-orientated backcasting. Pathway-orientated backcasting bridges the gap between the mere technical possibilities of today and the actions of tomorrow, answering the question "how can change take place?" It helps identify such critical non-technical triggering measures as planning processes, policies, taxes, and behavioural change. Furthermore, in action-orientated backcasting "what" and "how" are being complemented by focusing on answers to the question "who could make the change happen" through identifying actors and stakeholders, either from a list of predetermined actors, or through a more exploratory approach. Emancipatory backcasting is a scenario methodology with the goal of providing stakeholders with deeper futures perspective on activities they themselves initiate and undertake. In this sense it helps provide an understanding of cities and metropolitan regions as transitory, soft spaces. (Neuvonen et al. 2014).

Emancipatory backcasting resembles a looser methodological framework of visioning: a planning process used to develop specific goals and objectives for the future along with practical solutions, usually realised through consensusbased meetings open to all interested parties (McCann 2001). What these methodologies share is a notion of transformation towards desirable (low-carbon) futures which require innovation spurts and greater engagement of the different stakeholders of society instead of traditional regulation and top-down control. This is essentially the same goal as that of the incrementalism with perspective approach: to provide tools for governance that need to carry out larger scale yet gradual changes in a context (e.g. metropolitan spaces) that cannot be fully managed or controlled.

\section{Greater Helsinki Vision 2050 - A Case Study of Vision-Making and Backcasting ${ }^{1}$}

Helsinki is a smaller sized metropolis (using for example the OECD scale) that nevertheless shares many of the characteristics of bigger metropolises. The city is still growing in population, consolidating its role as the perennial engine of the Finnish economy, and expanding beyond previous municipal governance structures. Urban sprawl, funding of big infrastructure investments, allocation of tax revenues among municipalities and burden sharing on costs of public services among municipalities and between municipalities and the state are issues that underline the need for new planning and governance tools.

At the same time Helsinki is in fierce global competition for talent and international investments with other metropolises. This creates a need to constantly hone international brand of Helsinki as an inspiring and attractive city. In recent years Helsinki has gained plenty of positive attention internationally: it is consistently ranked in the top 5 on the list of the Quality of life survey by the Monocle magazine, in top 10 in The Economist Most Liveable Cities ranking and in top 10 in the world's most competitive cities ranking by IBM's Global Location Trends, all these rankings of course being highly selective with a new form of content marketing sponsored by cities and companies being used in them, and hence a mere reflection on the so-called relational world (Economist 2014, IBM 2013, Monocle 2014). Additionally Helsinki gained lot of media attention while holding the title of the World Design Capital in 2012 . If nothing else this media attention shows that Helsinki is gaining international good reputation as a metropolis. At the same time Helsinki faces the same internal challenges as practically all other metropolises: how to manage growth and how to focus growth spatially around effective traffic infrastructure and thus avoid excessive urban sprawl.

In 2006 the international ideas competition 'Greater Helsinki Vision 2050' (henceforth GHV 2050) was announced jointly by the region's fourteen municipalities, in cooperation with the Ministry of the Environment and the Finnish Association of Architects. The aim of GHV 2050 was to create a joint vision for the sustainable development of land use, housing and transport. The basic assumption of the brief was a rate of population growth similar to that in recent years, leading to an estimated 1.8 million inhabitants by 2050. At the same time the competition brief acknowledged the impact of society wide global trends, depicting multitude of changes occuring in economic, environmental, social and cultural spheres (Jury 2007).

The following changes and challenges were mentioned: climate change, the strain on ecosystems, sufficiency of capital for future investments, the changing structure of enterprises and industries, the attractiveness of spaces, spaces that enhance well-being, the tension between spaces of creativity and safety, places for tolerance and equality, places that support the potential of every child. The brief also specifically addressed the fact that there are both centralising and

\footnotetext{
${ }^{1}$ Both authors of this paper were involved in the Greater Helsinki 2050 follow-up process in charge of analyzing the competition results, planning the workshop process and building conclusions from results. Aleksi Neuvonen also participated in the GHV2050 competition as a member of the team behind the 'Towards City 2.0' entry that is also mentioned in the article. In this sense the research is made in a participant observation manner.
} 
decentralising forces at play in Finland, and that Helsinki needs to build a stronger brand and stronger clusters of innovation in order to succeed in global competition.

Altogether 109 entries were submitted by the deadline in 2007. Out of these, nine entries received an award, which was presented in December 2007. Following the jury protocol, which was published (Jury 2007), the competition assignment proved difficult. In keeping with the nature of a competition of ideas, the spectrum of entries was broad and the emphases varied considerably. (Ache 2011).

In the following sections the GHV2050 process is being described in three stages: competition entries, the competition follow-up process in 2008 and the post-follow-up process 2009-2014. In what follows we analyse the case of GHV2050 and its different stages in regards to how these stages exemplified the backcasting scenario approach - of course acknowledging the fact that the process was not originally officially planned as an exercise in backcasting.

\section{1 Backcasting 1: The GHV2050 Competition Entries}

The general focus of the entries is in depicting alternative futures for the region, its global status and competitiveness in the global economy. In more detail, they study different models for regional spatial structure, propose sustainable transport and residential solutions and explore new models of governance and cooperation. (Ache 2011)

The winning entry, Emerald, focused strongly on re-defining the 'urban form' of the metropolitan space. The team developed an urban programme comprising of several layers from building programs to infrastructure systems to green spaces.

Out of the three second-prize winners, Boundary Strips was concerned mainly with a new definition for the relation between nature and urban fabric and development of 'edges', Holistic Uniqueness on conceptualisation of different functional urban spaces (like the case of the 'global-localis', beyond a simple acceleration point and trying to define/refine physically the global in the local), while Towards City 2.0 tried to reach beyond built form in depicting the metropolis as a 'social silicon valley' (City 2.0) with the attempt to create a 'super diversity' fully employing citizens and their creative potential. The latter was actually the most interestingly developed contribution from a smaller group of similar concepts, which as such were underrepresented in an otherwise clearly 'urbanistic' approach towards the competition task. (Ache 2011)

In most entries the element of addressing future operating environments was widely present. These changes were defined in the competition entries through central megatrends relevant to metropolitan planning: climate change, ageing population, the rise of health and environmental awareness, ethical consumer behaviour, diversification and individualisation of lifestyles, changes in the nature of paid employment, and increases in work-based mobility were among the most frequently mentioned issues centred on change (Ache 2011).

The proposals were often built around measures that would provide the metropolitan region with either new spatial or new governance structures (Ache 2011). Among the regional spatial structures mentioned was the so-called finger model (based on the Copenhagen example, see Miljöministeriet 2007; Vejre, Primdahl \& Brandt 2007): off-shore extensions to the sea and green corridors or 'islands' excluding parts of the land from building and thus securing ecosystem services. In order to secure the necessary implementation power of these kinds of macro-level planning, many proposals suggested that municipal borders be either completely removed or at least that inter-municipal cooperation is strengthened, especially regarding the planning of land use. A wide range of softer (information and negotiation) governance tools were proposed to complement these comprehensive administrative tools: various regional electronic databanks, guide books, and collaborative forums were suggested in order to promote activity, market the region, and facilitate planning. An overall increase in open citizen participation was seen as vehicle for increasing the region's appeal, ensuring sustainable development, and strengthening residential roots.

However, behind these rather traditional top-down tools, one could spot ideas on branding and communication that would initiate new thinking, action and shaping of identities among residents and other stakeholders. Hence the entries gave rather detailed thought to the names and the organisation of different cooperative bodies, all the way through to their logos.

In interpreting this, it is quite evident that over the course of history large-scale building projects and reforms on governance structures have also served the purpose of sending a message to the people on the direction of progress (or development). Thus the idea of casting a perspective with the intention of engaging stakeholders into future-orientated action has been present. If not necessarily in the direct sense of creating a 'soft space' that would initiate imagination, then at least in the sense of producing a platform for 'hard space' showing the way for the rest of the activities. 
In the introduction part of this article we call for new tools of urban governance that would serve the needs of the 'Metropolitan Millennium'. We advocate an approach based on 'incrementalism with perspective' that would initiate (collective) imagination on the desirable futures of a region and the lifestyles it can accommodate. As a pragmatic tool for reaching these we suggested backcasting scenarios. Now the question is: did the awarded GHV 2050 competition entries provide exemplary cases of harnessing this approach and method?

The answer is - at least partially - yes: the majority of the awarded entries (with the exception of the highly formalistic entries 'Boundary strips' and 'LineTM') portrayed future metropolitan development in the Greater Helsinki Region also through 'soft spaces': lifestyles, work, participation and commerce. One should bear in mind that the original brief of the competition still emphasised solutions for the spatial planning and land use. Moreover, three entries (joint 2nd prize winning 'Towards City 2.0' and purchased entries 'Metroscape' and 'Thirdlife') provide backcasting-like timelines depicting a step-by-step transition between years 2006 and 2050. This method turned out to be widely used in the follow-up process of the competition.

\subsection{Backcasting 2: The Follow-up Process - Approaching Backcasting}

After the competition, a follow-up project was launched. The process was largely motivated by the jury suggestions: the jury did not follow the classic decsion to identify just one winner - and invited actors to use the potential embedded in all winning proposals to work on an integrated vision. What followed was a process that could be called backcasting: it (1) set a horizon of desirable alternative futures in the form of competition entries, (2) offered ingredients for constructing steps towards those futures (in the form of separate ideas identified from competition works), and (3) engaged stakeholders of the metropolitan region to envision alternative processes from different angles.

The process aimed at analysing the proposals, involving the views of the public and the municipalities and providing recommendations for further steps of the vision process. The main part of the follow-up process took place within the next 13 months after the competition decision. The process comprised of a deeper analysis of winning entries, a workshop with experts, and communication with the public. (The following parts are, unless otherwise indicated, based on Ache 2011.)

At the start of the follow-up process the research team, composed of representatives of the winning team, one of the three second place teams and a group of university researchers, analysed and restructured elements presented in the competition works. Based on this more than 250 'ideas' were identified. Further on, the team tried to identify synergies between ideas: solutions that would provide positive support for desired states of society, and address potential answers to the great challenges of society already visible today. These ideas and thematic 'ideas flocks' constructed from them formed the material for a series of workshops, in which city officials, the nine prize-winning teams, other planning experts and citizens evaluated the proposals in light of current social and pending environmental challenges.

By far the biggest of these workshops was the expert workshop. This workshop was supposed to elaborate elements for a regional vision and strategy, using the selection of ideas as a starting point. The session was initiated with a role-play session in which the participants were supposed to 'identify' with a new setting; i.e. adopt the point of view of a fictional future metropolitan citizen and evaluate the idea from that position. Based on the resulting descriptions the experts then assessed the ideas from their professional role.

In the second part of the workshop, participants had to 'evaluate' the ideas in the context of future challenges, and to gather the most promising elements for the future region. Based on this they discussed the elements and solutions towards an integrated vision. The future challenges were formulated in the following way: facing a multicultural society, finding a new work-life balance, heading towards a low carbon society, confronting the multiplication of lifestyles and values, improving the quality of the environment, and strengthening global competitiveness.

How to understand this process from our chosen vantage point 'incrementalism with perspective' and 'backcasting'? The workshop with its role-play intended to immerse the experts into a desirable future perspective, and to thus enable them to examine from a future point of view the criteria and conditions under which that future would come to be. Positioning them back to their expert roles and evaluating the ideas again was a way to create awareness on the necessary and sufficient elements for pathways between years 2007 and 2050. This is essentially the trick of backcasting scenarios: widening the horizon of the possible and providing enhanced understanding on time-scales of development.

The workshop can thus be considered in some respects a 'learning event'. It achieved a mutual confirmation of ideals or desired for situations. On the other hand, Neuman and Hull (2009) remind us that governance consists not only of learning but also 'un-learning' processes. In planning, un-learning is often about radical shifts or breaking well known paths, escaping mentally from 'path dependency' (Ache 2011). 
Also the quasi-official workshop report (WSP, Demos Helsinki \& YTK 2008) emphasises the communication function of the vision. The central purpose of the vision is to bring together the views of decision-makers, experts and the public on the future of the region, thereby committing everyone to the implementation of the joint vision in their operations. Another possible aim of the vision could be to demonstrate future directions and ambitions to the international community, thus strengthening the positive image of the region. Communicating the vision and committing all parties to it will be a long-term project, requiring continuous dialogue and public presence. In the Finnish context of strong municipal autonomy, the competition and its follow-up project are singular achievements. It is unique for municipalities within such a large region to engage in serious discussion about their common interests and future strategies. (Ache 2011)

The expert workshop was complemented by three shorter, open workshops for citizens and online discussion. These activities too were based on the idea of assessing the ideas extracted from the competition entries. The vision material and the ideas with most potential were compiled into a final report which acted as a basis and provided ingredients (like the title of report "Näkökulmia seutuvisioon" - "View-points to a regional vision" suggests) for the continuation of the vision process. The report also harnessed the backcasting approach: it presented the highlighted key implementation activities with a number of ideas from the competition works in the form of a future timeline, thus building bridges between inspiring future visions and more immediate and attainable steps.

The metropolitan region of Greater Helsinki is an institution in the making - competition entries and the follow-up work are to this day the most comprehensive forms of its existence. The Greater Helsinki Vision is instrumental in the creation of the new arena, addressing possible futures for the metropolitan space and creating a new action situation (Ache 2011). However, the follow-up process neither resulted nor was expected to result in a single vision statement. The report of the process was received by the Land-use, housing and transport collaboration group of the 14 municipalities but did not lead to any formal decisions.

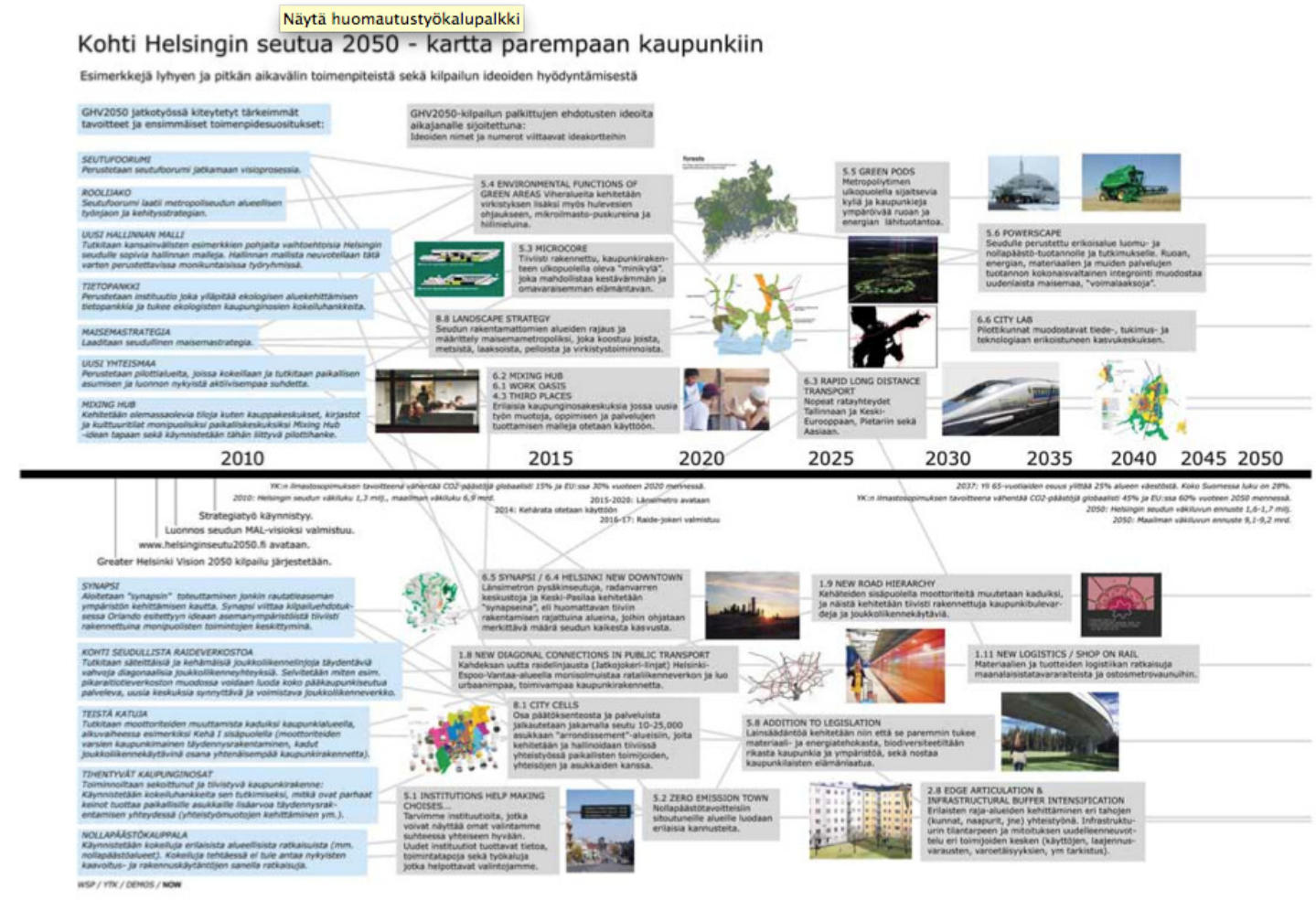

Image 1: A future timeline presenting the implementation activities 2008-2050 envisioned in the GHV2050 follow-up process, from the report Helsingin seutu 2050.

\subsection{Backcasting 3: The Post-Follow-Up Process}

The GHV2050 process took place within a context that included a substantial number of stakeholders and several parallel processes by them. Municipalities of the Helsinki metropolitan region in different constellations and through their different departments and different departments of the national government also worked on visions and strategies covering different sub-topics (economy and competitiveness; public service provision; traffic systems; land use; 
environment; goverance and public participation). The different stragies, visions and processes around them can be considered a 'visionary field' within which a co-evolution between different ideas could gradually emerge (Ache 2011). Also the action arena initiated by the GHV2050 follow-up process finally gave rise to a number of partly distinct processes that also partly converged towards other processes of the visionary field. So far the most systematic separate strategies have emerged on land use, transportation systems and housing.

After the follow-up process in 2008 the 14 municipalities of the Helsinki Region have gradually developed a shared 'brand' and first iterations of a joint process for strategic planning. At the end of 2009 the municipalities agreed a common vision for the region. The vision states that

The Helsinki Region is a dynamic world-class centre for business and innovation. Its high-quality services, arts and science, creativity and adaptability promote the prosperity of its citizens and bring benefits to all of Finland. The Metropolitan Area is being developed as a unified region close to nature where it is good to live, learn, work and do business. The harmonious urban structure of the region is based on public transport; it is versatile in its operations as well as eco-efficient and low carbon. The compact core area is encircled by a network of distinctive centres. (Helsingin seudun yhteistyökokous 2009)

This 'vision' itself does not require very complicated analyses. Firstly, it does not set a clear vision in the sense of depicting something to be achieved in the future, but mostly dwells on directions of development and (technical) criteria for an efficient regional spatial structure. It also states rather obvious and commonly held views on the economic strengths of any European metropolis: a knowledge based economy and high quality of living are the competitive assets through which most of the post-industrial cities endeavour to prosper. Hence the vision names the lowest common denominator for a desirable future that the 14 (in part greatly differing) municipalities share. In terms of the written vision itself the GHV2050 did not result in an outcome that would make it stand out from all the other city and metropolitan visions of the world. But the process is still ongoing: a vision is often just a shared platform for initiating something more substantial.

The vision has indeed provided a steady platform for formalising the structures of cooperation. One piece of evidence for this is that the 14 municipalities have adopted a shared brand, calling themselves the 'Helsinki Region' (omitting 'Greater'), which has its own website that serves both as a service database for citizens and as an information channel for regional cooperation. However, the website is a low-profile one, the main digital marketing and service platforms of the municipalities being established elsewhere.

There are three parallel planning processes currently running in the municipalities of the Helsinki Region: one on landuse, another on housing and a third on transportation. The shared land-use plan for the Helsinki Region is due to be finalised in 2015. Its implementation time frame is 2025, with generic frames for urban and regional structures until 2050. The emphasis in this work is in assessing impacts and setting priorities for choosing the areas in which to build. The regional plan is part of an agreement between the government and the 14 municipalities that covers the term of the current national government. (Helsingin Maankäyttösuunitelma 2014)

With regard to housing, the previous agreed goal among municipalities is to build 12500 new flats annually. However, the current regional housing strategy aims at updating the forecast on housing needs and also revisiting this target. A joint housing strategy is to be completed by 2015 .

The regional transportation system plan has a longer history dating back to the pre-GHV2050 era. Previously it covered the Helsinki area comprising of Helsinki and the three neighboring cities. Already at the time of the GHV2050 this process was extended to include the next layer of municipalities. The new transportation system plan is also underway and to be completed in 2015. (Helsingin seudun liikennejärjestelmäsuunnitelma 2014)

Meanwhile the political debate both on the regional and on the national level has dealt with forming legally authorised governance structures for the metropolitan region. In national politics reforming the municipal structures has been one of the biggest and the most complex debates in recent years with none of the political parties or coalitions being capable of formulating clear suggestions for a required reform.

Since Finnish municipalities carry broad duties in service provision (and corresponding rights to collect taxes) in addition to land use planning power, the core motivations for structural reform has remained obscure for a large proportion of the citizens. In the Helsinki metropolitan region and in regions around the biggest cities the need for greater collaboration among municipalities has mainly arisen from the need to coordinate better land use planning and housing policies and to commit all municipalities to the required investments in traffic infrastructure (and eventually slowing down the urban sprawl created by freewheeling planning policies of fringe municipalities favoring single family housing and large hyper markets). Meanwhile, in rural regions the focus of debate has been in forming regions with large enough populations in order to have sufficient resources to efficiently provide the health and social services required by national law. 
However, the public discourse has often left unclear whether reform in Helsinki metropolitan region is motivated by the needs of land-use planning or by demand for efficient service provision. During the current electoral term all the bigger urban regions have been required to agree on targets concerning land-use, housing and transportation (so called MALagreements) in order to be eligible for government funding for large scale infrastructure projects. There is also a national coordination unit that supports agreement processes by providing information and running pilot projects with the hope of producing benchmark cases for different forms of cooperation among municipalities.

At the end of August 2014 the coalition agreed to continue the series of structural reforms by introducing a new layer of administration to the metropolitan region. The first regional council will be elected in 2016 and the new auhtority will start operating in 2017. The government decision did not provide the new authority with rights to collect taxes, meaning that the national government and the municipalities still have to agree on how to share the economic burden of the new system.

Once again returning to our point of departure, incrementalism with perspective and backcasting: are there any examples to be seen of the approach or the method? It is quite apparent that the processes have converged towards the standard arenas of regional governance, existing structures of land-use and transportation planning. In this sense the GHV2050 process could be interpreted as a catalytic step towards deeper cooperation among the municipalities: it offered a platform for neutral and conflict free discussion on the future and provided supporting elements for the new agenda that united the group of more or less like-minded professionals of land-use planning. However, once the issues started to gradually move along the traditional path (land-use and transportation planning processes) the more holistic and comprehensive approach on society-wide change have taken a back seat.

Yet the planning criteria (approved in April 2014), applied to both the land-use and the transportation system plan, still retains the backcasting-like approach to long-term change. The criteria determine the plans to be presented in the form of a long-term structural plan (reaching beyond 2050) an implementation plan (up until 2025). It is also mentioned that there should be a vision depicting the solutions to be reached by year 2040. (Helsingin seudun yhteistyökokous 2014)

Previously long-term vision had no formal status in Finnish planning system. Nor had it been stated that there should be several separate interim goals on the way towards this vision. In this respect we once again come across the idea of setting a 'perspective' and backcasting, or tracing it then gradually along the timeline towards the more immediate future, where concrete solutions can already be implemented.

\section{Analysis}

The Greater Helsinki Vision 2050 process has been presented as a promising example case of a new metropolitan governance tool. Back when the process took place (2006-2008) it professed several characteristics that were in many ways special compared to standard measures of regional governance. The very idea of organising an open international ideas competition in the first place was a message on how metropolitan regions should be perceived: metropolitan spaces are essentially nodes of the global economy and culture, hence the solutions to their challenges should be developed within the global realm.

This same approach is also part of the so called Open Knowledge movement that has over the past years challenged both the public and the privately owned companies to open their (digital) data to everyone and thereby to maximise the stock of information, the key resource of our current economy, for joint problem solving. A number of international cities, Helsinki among them, have adopted the open data agenda and shown high-level commitment (mayors being visible advocates of the issue) to mainstreaming open practices.

In a previous article Ache (2011) has suggested that the GHV2050 could also be seen as an example of managing by 'irritation' or 'shock': the competition could be considered a challenge to the dominant institutions to reform their approach and practices. The competition introduced and assumed the idea of our era being characterised by a number of disruptive changes that require a longer than usual time horizon and a more comprehensive view on society. Thus the implicit claim that the current structures of governance limit problem-solving capacity in the face of future challenges. What is needed - and what was required in the competition brief - is a more interdisciplinary approach to metropolitan planning, reaching out from the territory of spatial planning. In a sense the competition conveyed this new agenda to the incumbent actors (spatial planning civil servants in the municipalities).

Yet a substantial part of the GHV 2050 process was focused on building ownership to planning professionals on shared vision and elements around which it was gathered: in the follow-up workshop experts had the opportunity to explore the vision elements extracted from the competition submissions further and to attempt to compose a shared vision. It was a communicative approach that tried to grasp central intentions and to validate critically the vision elements from an expert point of view (Ache 2011). The further the (post-)process moved the more the competition entries were 
understood as explorations into the built forms of the future metropolis. In this sense it could be assumed that the vision had an 'implicit' or 'catalytic' effect on the governance of the Helsinki Region. It gathered and ignited a new coalition of like-minded civil servants around a novel shared agenda. Perhaps this 'emergent agenda' (Mintzberg 1994) can keep the processes around Helsinki Region long-term planning despite coming and going political impasses, hence making the process of metropolitan level planning more difficult to stop politically (Ache 2011).

The crucial question remains: was the process intended (by the people who initiated the GHV 2050 process) to take this direction? Was the only possible outcome that the competition would give fresh impetus to deeper cooperation in landuse planning between the Helsinki Region municipalities? Or could the process have resulted in something completely different: a vision with radical reframing of the agenda on the metropolitan future, or a new type of process engaging new actor groups and breaking the existing silos of the regional governance?

A kind of 'visionary field' emanates from various institutions and actors - there has to be some kind of ownership and definition of a field under discussion. Therefore the resulting visions correspond at least partially to agreed functions and perform specific tasks designated to the respective institutions. Some of the agendas around visions can be considered 'free format', stretching the existing administrative and political horizons. In this sense, an outward-looking exercise carries a learning function and prepares regional actors for coming challenges. In principle we do not have any reason to assume there to be a definitive limit on how long this learning process can move the actors. Usually, though, the limiting factor is embedded in the implementation capabilities of the actors involved: most of the resources in institutions are tied to old problems and thesis solutions and therefore the actors lack the resources to explore novel solutions to emerging challenges (Auerswald 2012).

It is plausible to think that the process would have given different results had it all happened five years later. In 20072008 Finland was only on the threshold of the social media era (the number of Facebook users started to grow in Finland in late 2007, and the complete Finnish version was launched in the summer of 2008). The open data movement started to gain popularity in 2010. Both the agenda and the arenas of the public discussion could have looked quite different had these tools been in place at the time of the GHV 2050 process.

\section{Conclusions and questions for further research}

In this paper we have assessed the Greater Helsinki Vision 2050 process from the point of view of the incrementalism with perspective approach, and as an example of backcasting. We have tried to analyse whether a process like the GHV2050 could be seen as an example of new governance tools for metropolitan regions and for solving the wicked problems metropolises need to cope with.

Based on our observation,s the backcasting approach was deployed in the GHV2050 process primarily as a tool for empowering the key stakeholders (the planning professionals from the 14 municipalities) - to imagine the alternative sustainable futures of the metropolitan spaces and to name essential steps for achieving those desirable goals. To this end it is an example of emancipatory backcasting (Neuvonen et al. 2014), or pathway-oriented backcasting (Wangel 2011) that does not focus on mere technical possibilities, but aims to function as a bridge towards future-oriented action. Hence what resulted was strategic learning (Hay, cited in Allmendinger 2009), in which the actors involved reinterpreted the surrounding structures, which subsequently enabled them to grasp new opportunities (and most likely also new constrains) for action. The depth and impact of this learning process on the level of individuals who participated in the GHV2050 process would need to be elaborated further through an interview study.

However, the element of strategic learning in the overall GHV2050 process would probably have been substanially stronger had there been a more ambitious and better integrated process to engage citizens and other stakeholders than civil servants. That could potentially have resulted in a wider action arena that would have had impacts reaching beyond institutional structures. A comparative study on a similar process with more ambitious stakeholder engagement could shed light on the question of the type of impact that wider stakeholder engagement has.

However, as the example also shows, the specific vision process under consideration was from the beginning embedded in a field of vision and strategy-making. Whereas the process itself aimed to be (and also succeeded in being) a learning process (ownership), it also experienced a setback in the subsequent processes that returned to classic formats and implementation processes. Nevertheless, as has been shown, this reflects the existing institutional structures and inertias: the main challenge will be to merge the fourteen cities (and the entire region) into a single new metropolitan organisation, while avoiding the creation of a mere superstructure perpetuating the existing framework.

\section{References}


Ache, P 2011, "'Creating futures that would otherwise not be" - Reflections on the Greater Helsinki Vision process and the making of metropolitan regions', Progress in Planning, vol. 75, pp. 155-192. Available from: Science Direct. [5 September 2014].

Ache, P 2013, Between vision and response capacity - configuring metropolitan development, inaugural speech by Prof. Dr. Peter Ache. Available from: Radboud Repository. [5 September 2014].

Alanen, O, Hautamäki, A, Kaskinen, T, Kuittinen, O, Laitio, T, Mokka, R, Neuvonen, A, Oksanen, K, Onnela, S, Rissanen, M, Vassinen, S, Viljanen, V 2010, The Well-Being of the Metropolis, Demos Helsinki, Helsinki.

Allmendinger, P 2009, Planning Theory (2nd edition), Palgrave Macmillan, Basingstoke.

Allmendinger, P \& Haughton, G 2010, 'Spatial planning, devolution and new planning spaces', Environment and Planning C: Government and Policy, vol. 28, pp. 803-818.

Auerswald, P 2012, The Coming Prosperity: How Entrepreneurs Are Transforming the Global Economy, Oxfored University Press, New York.

Campbell, S 1996, 'Green Cities, Growing Cities, Just Cities?', Journal of the American Planning Association, vol. 62, no. 3, pp. 296-312.

Dreborg, K 1996, 'Essence of backcasting', Futures, vol. 28, no. 9, pp. 813-828.

Economist 2014, 'The best places to live', The Economist daily chart 19 August. Available from: $<$ www.economist.com>. [6 September 2014].

European Commission 2011, 'A Roadmap for moving to a competitive low carbon economy 2050', Communication from the Commission to the European Parliament, the Council, the European Economic and Social Committee and the Committee of the Regions. Available from: EUR-Lex. [6 September 2014].

Florida, R 2005, ‘The World Is Spiky', The Atlantic Monthly October 2005, pp. 48-51.

Friedmann, J 2002, The prospect of cities, University of Minnesota Press, Minneapolis.

Fuenfschilling, L \& Truffer, B 2014, 'The structuration of socio-technical regimes - Conceptual foundations from institutional theory', Research Policy, vol. 43, pp. 772-791. Available from: Science Direct. [5 September 2014].

Ganser, K, Siebel, W \& Sieverts, T 1993, 'Die Planungsstrategie der IBA Emscher Park - Eine Annäherung', RaumPlanung, vol. 61, pp. 112-118.

Geels, F 2002, 'Technological transitions as evolutionary reconfiguration processes: A multi-level perspective and a case-study’, Research Policy, vol. 31, no. 8-9, pp.1257-1274.

Geels, FW 2011, 'The multi-level perspective on sustainability transitions:

Responses to seven criticisms', Environmental Innovation and Societal Transitions, vol. 1 pp. 24-40.

Geertz, C 1973, 'Thick Description: Toward an Interpretive Theory of Culture', in The Interpretation of Cultures: Selected Essays, Basic Books, New York. pp. 3-30.

Giddens, AT 1984, ‘The Constitution of Society. Outline of the Theory of Structuration', Polity Press, Cambridge.

Government Office for Science 2010, Land Use Futures: Making the most of land in the $21^{\text {st }}$ Century, Executive Summary, London.

Helsingin Maankäyttösuunnitelma 2014, 'Maankäytön, asumisen ja liikenteen seutuyhteistyö', Helsingin Maankäyttösuunnitelma. Available from: <http://www.helsinginseutu.fi/hki/HS/Maankayttosuunnitelma/Maankayttosuunnitelma/mika+mal>. [6 September 2014].

Helsingin seudun liikennejärjestelmäsuunnitelma 2014, HLJ 2015. Available from: <https://www.hsl.fi/hlj>. [6 September 2014]. 
Helsingin seudun yhteistyökokous 2009, Helsingin seudun visio. Available from: <http://www.helsinginseutu.fi/hki/hs/helsingin+seutu/yhteisty_elimet/helsingin+seudun+yhteisty_kokous/helsingin+seu dun+visio>. [6 September 2014].

Helsingin seudun yhteistyökokous 2014, Helsingin seudun yhteistyökokouksen esityslista 13.5.2014. Available from: <http://www.helsinginseutu.fi/hki/hs/Helsingin+Seutu/Yhteisty_elimet/Helsingin+seudun+yhteisty_kokous/Esityslistat/ El+Hsyk+1+2014>. [6 September 2014].

Hillier, J \& Healey, P (eds.) 2008, Foundations of the planning enterprise. Critical essays in planning theory (vol. 1), Ashgate, Aldershot.

Hutter, G 2006, 'Strategische Planung. Ein wiederentdeckter planungsansatz zur Bestandsentwicklung von Städten', RaumPlanung, vol. 128, pp. 210-214.

Höjer, M, Mattsson, L 2000, 'Determinism and backcasting in future studies’, Futures, vol. 32, pp. 613-634.

IBM Institute for Business Value 2013, Global Location Trends - 2013 annual report. Available from: $<$ www.ibm.com/iibv>. [6 September 2014].

Jury 2007, Greater Helsinki Vision 2050 - International Ideas Competition, Jury Protocol, SAFA, Helsinki.

Massey, D 2005, For Space, Blackwell, Oxford.

McCann, E 2001, 'Collaborative Visioning or Urban Planning as Therapy? The Politics of Public-Private Policymaking', The Professional Geographer, vol. 53, no. 2, pp. 207-218. Available from: Wiley Online Library. [6 September 2014].

Miljöministeriet 2007, Fingerplan 2007. Landsplandirektiv for hovedstadsomradets planlaeging, Miljöministeriet, Copenhagen.

Mintzberg, H 1994. The rise and fall of strategic planning, The Free Press, New York.

Monocle 2014, 'Quality of Life Survey 2014' (video), Available from: <http://monocle.com/film/affairs/quality-of-lifesurvey-2014/>. [6 September 2014].

Neumann, M \& Hull, A 2009, ‘The futures of the city region', Regional Studies, vol. 43, no. 6, pp.777-787.

Neuvonen, A, Kaskinen, T, Leppänen, J, Lähteenoja, S, Mokka, R \& Ritola, M 2014, 'Low-carbon futures and sustainable lifestyles: A backcasting scenario approach', Futures, vol. 58, pp. 66-76. Available from: Science Direct. [5 September 2014].

Helsingin seutu 2050 - Näkökulmia seutuvisioon. Jatkotyö Greater Helsinki Vision 2050 - kansainvälisen ideakilpailun palkittujen töiden pohjalta 2008. Helsingin kaupungin talous- ja suunnittelutoimiston julkaisuja 5/2008. Helsinki.

Quist, J, Vergragt, P 2006, 'Past and future of backcasting: The shift to stakeholder participation and a proposal for a methodological framework', Futures, vol. 38, no.9, pp. 1027-1045.

Rittel, HWJ, Webber, MM 1973, 'Dilemmas in a general theory of planning', Policy Sciences, vol. 4, no. 2, pp. 155169.

Taylor, P 2004, World city network. A global urban analysis, Routledge, London.

Vejre, H, Primdahl, J \& Brandt, J 2007, 'The Copenhagen finger plan. Keeping green space tructure by a simple planning metaphor', in Europe's Living Landscapes, eds B Pedroli, A Van Doorn, G d Blust, ML Paracchini, D Wascher \& F Bunce, KNNV Publishing, Zeist, pp. 310-328.

Veltz, P 2004, 'The rationale for a resurgence in the major cities of advanced economies'. Paper presented at The Resurgent City, Leverhulme International Symposium 2004.

Wangel, J 2011, 'Exploring social structures and agency in backcasting studies for sustainable development', Technological Forecasting \& Social Change, vol. 78, no. 5, pp. 872-882. 
WSP, Demos Helsinki \& YTK 2008, 'Greater Helsinki Vision 2050', International ideas seminar, Summary report, WSP, Helsinki.

Aleksi Neuvonen is the founder and Head of Foresight at Demos Helsinki, the Nordic think tank specialised in combining foresight and co-creation. At Demos Helsinki he oversees systemic, future-oriented research that aims to apply creative methods to behavioural change, design thinking, prototyping and business modelling. Neuvonen is a futures researcher, whose special interests lie in the fields of urban development and lifestyle changes. He is currently preparing his $\mathrm{PhD}$ dissertation on the use of backcasting scenarios in urban transitions towards a low-carbon society at the Radboud University Nijmegen (NL) and theTampere University of Technology (FI).

Peter Ache is Professor of Planning at the Radboud University Nijmegen (NL) since 2012. He supervises a group of twenty researchers, working on different topics such as local and area development, water management, and mobility research. Project activities include e.g. Transport and Planning Scenarios. Ache is a spatial planner with a doctoral degree from TU Dortmund, Germany. His research interests are in large-scale development processes and visionmaking in metropolitan regions. Ache is a member of the German-based ARL and DASL. He is also active in the Association of European Schools of Planning, of which he was president in years 2006-2008. 